The Pacific Islands region occupies a vast

ocean continent, consisting of a diversity of cultures. What draws the islands together is a shared experience of economic dependency and vulnerability driven by global warming, geopolitical competition, and class divisions. Together, these factors account for poor performance on a range of development indicators, including policy and inequality. It is in this context that Epeli Hau'ofa has argued that the hoped-for era of autonomy following political independence has not materialised in the Pacific. In response, this paper explores the possibilities and potential aims of a Left secretariat in the Pacific. It aims to rethink political and economic autonomy in the Pacific by bringing together Left theory and practice with the history of Indigenous and class struggles. 


\section{Towards a Left Secretariat for the Pacific}

\section{TIM BRYAR}

The Pacific Islands inhabit the largest ocean in the world, situated between the Americas to the East and Asia to the West. While all the nations of the Pacific were colonised (save Tonga, which became a British protectorate in 1900 to avoid colonisation by the Germans), some more than once, both their experience of colonialism and their postcolonial status varies. Today there are nine fully independent Pacific Island countries, five semi-autonomous countries, and five territories. ${ }^{1}$ While there is great cultural diversity in the region, it is typically considered to consist of three sub-cultures: Polynesian, Micronesian, and Melanesian. The region is also economically diverse, with island economies often categorised in one of three ways: MIRAB (Migration, Remittances, Aid, and Bureaucracy); SITE (Small Island Tourist Economies); and PROFIT (People, Resource Management, Oversea Engagement, Finance/Insurance/

1 For the purposes of this paper, the term 'Pacific' refers to all the island nations and territories, regardless of their political status. The independent nations are Fiji, Papua New Guinea, Vanuatu, Solomon Islands, Samoa, Tonga, Kiribati, Tuvalu, and Nauru. Semiautonomous nations are Niue, the Cook Islands (associated with New Zealand), Palau, the Federated States of Micronesia, and the Marshall Islands (associated with the United States). The territories are Guam, the Commonwealth of the Northern Marianas, and American Samoa (United States), and French Polynesia and New Caledonia (France). 
Taxation, and Transportation). ${ }^{2}$

Despite these differences, countries of the region share a range of common and interrelated vulnerabilities and dependencies. Indeed, the future viability of Pacific Island nations remains highly uncertain. The impacts of global climate change present an existential threat to many island countries: current trajectories of global temperature rise will make many uninhabitable by the end of the century, if not sooner. ${ }^{3}$ Pacific economies are also vulnerable to environmental shocks and global economic crises (including the current economic crisis triggered by the pandemic). For example, cyclone Pam, which devastated Vanuatu in 2015, caused economic losses equivalent to 64.1 percent of its $\mathrm{GDP}^{4}$ The deficits resulting from small productive capacities and economic fragility are largely offset by a heavy dependence on foreign financial aid; when measured by aid inflows as a proportion of GDP, the Pacific remains the most aid-dependent region in the world. 5 Somewhat tragically, the most attractive option for island states today appears to be to leverage their vulnerability to access greater financial aid (in the last decade, the region has accessed almost US $\$ 2$ billion in climate-change financing).

The combination of these vulnerabilities and dependencies underpins the generally weak development across the region. ${ }^{6}$ Today, one-quarter of Pacific Islanders live below the basic-needs poverty line, with some analysts

2 For in-depth discussion on these categorisations, see Geoff Bertram, 'Introduction: The MIRAB Economy in the Twenty-First Century,' Asia Pacific Viewpoint 47, no. 1 (2006): 1-13.

3 Intergovernmental Panel on Climate Change, 'Global Warming of $1.5^{\circ} \mathrm{C}$. An IPCC Special Report on the Impacts of Global Warming of $1.5^{\circ} \mathrm{C}$ Above Pre-Industrial Levels and Related Global Greenhouse Gas Emission Pathways, in the Context of Strengthening the Global Response to the Threat of Climate Change, Sustainable Development, and Efforts to Eradicate Poverty,' Geneva, IPCC, 2018.

4 International Labour Organisation, 'Cyclone Pam causes devastating impact on employment and livelihoods,' ILO, 23 April 2015.

5 Alexandre Dayant, 'Follow the money: how foreign aid spending tells of Pacific priorities,' The Interpreter, 17 April 2019.

6 Pacific Islands Forum Secretariat, 'Report to Pacific Leaders,' Suva, PIFS, 2013; 'First Quadrennial Pacific Sustainable Development Report,' Suva, PIFS, 2018. 
estimating that this could rise to 40 percent as a result of the economic impacts of Covid-19. ${ }^{7}$ Economic inequality is also on the rise. Surveys in five countries in the region have shown that, on average, the bottom quintile accounts for 4.5 percent of total household income, while the top quintile accounts for 52.3 percent. $^{8}$ It was recently reported that Fiji is home to 527 millionaires; but this should be juxtaposed to the woefully low minimum wage of FJ $\$ 2.68$ per hour (with 35 percent of workers earning less than FJ $\$ 2.90$ per hour). ${ }^{9}$ Climate change is also anticipated to impact on the future of tuna fisheries and tourism, two of the key economic sectors in the region. ${ }^{10}$

As renowned Tongan anthropologist and writer Epeli Hau'ofa has argued, the hoped-for era of autonomy following political independence has not materialised in the Pacific. ${ }^{11}$ This failure is no simple accident of history; it is the result of the incorporation of the region into the global capitalist economy, and of the actions of former colonial powers seeking to ensure their strategic and commercial interests remain protected. ${ }^{12}$ Indeed, Hau'ofa locates the problem of autonomy within the emergence of what he terms 'The New South Pacific Society', characterised by transnational class divisions, where an elite class have privileged access to, and control of,

7 Chris Hoy, 'Poverty and the pandemic in the Pacific,' DevPolicy Blog, 15 June 2020.

8 PIFS, 'State of Pacific Regionalism Report,' Suva, PIFS, 2017.

9 Selita Bolanavanu, '527 Millionaires in Fiji,' Fiji Sun, 27 October 2017; Dhanjay Deo, 'Bala says over $96 \%$ workers earn over 2.68 /hour while Anthony believes the wage rate is low,' Fiji Village, 20 February 2020.

10 IPCC, 'Special Report on the Ocean and Cryosphere in a Changing Climate,' Geneva, IPCC, 2019.

11 Epeli Hau'ofa, 'Our Sea of Islands,' in We are the Ocean: Selected Works (Honolulu: University of Hawai'i Press, 2008), 27-40.

12 Geoff Bertram, 'The Political Economy of Decolonisation and Nationhood in Small Pacific Societies, in Class and Culture in the South Pacific, eds. Anthony Hooper et al (Auckland: Auckland University Press, 1987), 16-31; Feleti Sevele, 'Aid to the Islands Reviewed,' in Class and Culture in the South Pacific, 71-77. 
resources moving within, and to and from, the region. ${ }^{13}$ Rather than the emergence of self-reliance, the post-colonial era has witnessed deepening economic dependency and social integration with Australia and New Zealand. 'It follows that what we call national sovereignty in the region is little more than a measure of local autonomy in the hands of competing national interests within the larger regional economy. These interests are represented by the ruling groups within each community'. ${ }^{14}$

Several authors have observed how the Pacific elite are reshaping culture and tradition in Pacific countries so as to secure greater advantages for themselves. ${ }^{15}$ As Hau'ofa observes, 'it is the poor that have to live out culture; the privileged can merely talk about it and be in a position to be selective about what traits they use or more correctly urge others to observe'. ${ }^{16}$ One would do well to recall, then, that while Pacific colonial histories certainly consist of protest and dissent against the domination of colonial settlers, protest was also mounted against those Indigenous elites who exercised power and privilege over island societies. ${ }^{17}$ Perhaps this is how we should interpret Albert Wendt's assertion that 'Our quest is not for the revival of past cultures but for the creation of new ones which are based on our own pasts and which are free of the taint of colonialism'. ${ }^{18}$ That is, we must challenge and expand the post- and anti-colonial frameworks that dominate discourses of power and resistance in the region, and draw on the history of class struggle in the Pacific.

Responding to the context outlined above, this paper explores the possibilities and potential aims of a Left secretariat in the Pacific. It aims

13 Epeli Hau'ofa, 'The New South Pacific Society: Integration and Independence,' in We are the Ocean, 11-26; Vijay Naidu, 'Fiji: The State, Labour Aristocracy and the Fiji Labour Party,' in Class and Culture in the South Pacific, 210-229.

14 Hau'ofa, 'The New South Pacific Society,' 21.

15 Albert Wendt, 'Towards a New Oceania,' Mana Review 1, no. 1 (1976): 49-60; Hau'ofa, 'The New South Pacific Society'.

16 Hau'ofa, 'The New South Pacific Society,' 14.

17 Peter Rutherford and Noel Hempenstall, Protest and Dissent in the Colonial Pacific (Suva: University of the South Pacific, 1984).

18 Wendt, 'Towards a New Oceania,' 53. 
to rethink political and economic autonomy in the Pacific by bringing together Left theory and practice with the history of Indigenous and class struggles. The first section provides some reflections on the reception of Left political theory in the Pacific Islands region; the second section then seeks to outline some possible aims and functions of a Left secretariat for the Pacific. This is not the first time an attempt has been made to bring Left political theory in contact with Pacific worldviews and anti- or postcolonial thinking in the Pacific. As it was earlier, such a project today is no doubt fraught with sensitivities and challenges. I will not attempt to address these in this short intervention. But I do want to acknowledge that such challenges exist and argue that the production of a transformative politics from within the region could benefit from bringing together Left theory and practice with Pacific histories of Indigenous, anti-colonial, and class struggles.

I make this proposal as a white Australian male, born and raised in Melbourne, who has made Fiji and the Pacific his home since 2006. I recently resigned from seven years at the Pacific Islands Forum Secretariat (a secretariat to a regional collective of 18 prime ministers and presidents from the Pacific, including Australia and New Zealand), serving first as the conflict prevention adviser and then as a senior policy adviser to the secretary general. In the Leftist tradition, I would perhaps consider myself to be Marxist-Leninist, and I am most inspired by the theoretical edifice of Slavoj Žižek. These frames provide a key part of my independent research and writing in the Pacific. ${ }^{19}$

\section{What's Left in the Pacific?}

In the Pacific, the 1980s (the decade following independence) was a period of heightened political struggles that, in different ways, were engaged with the interactions between capitalism, indigeneity, and colonialism, including

19 See: www.oceaniahypothesis.com 
the movement for a Nuclear Free and Independent Pacific (NFIP), the Bougainville revolutionary movement, and the 1987 military coup in Fiji. The 1987 coup, for example, was grounded in a rhetoric of Indigenous paramountcy against the rise of multi-ethnic political power. However, one of its indirect outcomes was the introduction of the structural adjustment policies of the World Bank and International Monetary Fund. ${ }^{20}$ In contrast, the Bougainville revolution was as much an anti-capitalist movement as it was a struggle for national independence. In an unsourced document written by the figurehead of the revolutionary movement, Francis Ona, it is described how people in Bougainville 'are the "sacrificial lamb" for the few capitalists whose hunger for wealth is quenchless and unceasing. . . We are not going to sit by and watch capitalists and their Papua New Guinean political allies exploiting us'. ${ }^{21}$

Along with heightened political struggle, the 1980s witnessed a flurry of writing and analysis on the political economy of the region, inspired by neo-Marxist frameworks. ${ }^{22}$ Amongst other things, these analyses emphasised how the post-colonial period had led to the entrenchment of class divisions and an increased dependency on financial aid, while also deepening integration into regional and global economies in ways that promote economic insecurity for Pacific states. Underpinning these issues were a range of structural factors that placed the Pacific on the 'extreme periphery' of global capitalism. This emergence of neo-Marxist thinking and research in the Pacific was not without controversy, and was actively resisted by more traditional social and historical theorists. ${ }^{23}$

Today, such analysis has all but disappeared, largely giving way to postcolonial and identity politics and an entrenched opposition between Pacific

20 Haroon Akram-Lodhi, 'Structural Adjustment in Fiji under the Interim Government, 1987-1992,' The Contemporary Pacific 8, no. 2 (1996): 259-290.

21 Francis Ona, unsourced document, 29 November 1989, 3.

22 See, for example, Michael Howard et al, The Political Economy of the South Pacific (Townsville: James Cook University, 1983); Hooper et al, Class and Culture in the South Pacific.

23 Michael Howard, 'Social Scientists in Paradise,' Journal of Pacific Studies 9 (1983): 1-8. 
culture on the one side and Western capitalist culture on the other. This has produced an emphasis on cultural autonomy as a dominant theme in political theory and action in the region. For example, while for Hau'ofa the quest for autonomy needs to be fought on multiple fronts, he nonetheless places great emphasis on the idea of cultural autonomy. As Hau'ofa argues: the creative arts are 'necessary tools for the attainment and maintenance of autonomy within a homogenising global system. Our social, economic and political institutions are woven into the larger world system; any free space within will have to be established through creative cultural production'. ${ }^{24}$ In this way, cultural autonomy is constructed as an asymptotic 'last point', forever escaping modernity's capture. ${ }^{25}$ Similarly, while Wendt acknowledges the problems of both economic and cultural dependency, he nonetheless claims that cultural dependency is even more soul destroying than economic dependency, because it debases Pacific pride, self-respect, and self-reliance, which are all necessary for full decolonisation. ${ }^{26}$

Some of the practical outcomes of this emphasis on cultural autonomy are that rather than being overwhelmed by global capitalism, Pacific Islanders have 'discerning attitudes to their engagements with capitalism; embedding market patterns within the indigenous economic forms that continue to give their lives meaning, whist yielding economic autonomy' ${ }^{27}$ The idea that culture can provide a sovereign space of freedom and autonomy within the global capitalist system has inspired activists, academics, and politicians across the Pacific. For example, Pacific governments have developed 'uniquely Pacific' forms of international diplomacy, celebrated

24 Epeli Hau'ofa, 'Our Place Within: Foundations for a Creative Oceania,' in We are the Ocean, 81.

25 Saroj Giri, 'Parasitic Anti-Colonialism,' in The Final Countdown: Europe, Refugees and the Left, eds. Boris Buden et al (Ljubljana: Irwin, 2017).

26 Wendt, 'Towards a New Oceania,' 49-60.

27 Rachel Smith, 'Engaging with Capitalism: Cases from Oceania,' The Asia Pacific Journal of Anthropology 16, no. 1 (2015): 84. 
by academics in the region as the 'New Pacific Diplomacy', a form of Indigenous diplomacy inspired by artistic, literary, and academic cultural production. ${ }^{28}$

However, to what extent can one claim a space of cultural autonomy within global capitalism? And what impact does the assertion of cultural autonomy have on the possibility for struggles against capitalism in the region? Indeed, a common assertion of Left political theory is that there is no space of autonomy outside the reach of capitalism, that everything, including our resistance to it, gets drawn back into the logic of capital. Indian academic Saroj Giri provides an outstanding critique of anti- and post-colonial resistance that addresses these concerns. ${ }^{29}$ Giri shows how an abstract frame of the 'colonial rule of difference' (for example, the West versus the non-West), sustained by both the construction of a hyperbolic external power ('the colonial capitalist West') and an autonomous space of Indigenous sovereignty denied to the West, together provide the ideological scaffolding for sustaining existing class and power relations. Or, applied to the context of this paper, the insistence on cultural autonomy made by Hau'ofa and others may sustain the social relations of the New South Pacific Society by masking the participation of the local elites in (and the desire of the middle class for) the dominant Western capitalist culture. Although the colonial power is denied access to this inner domain, the outer domain nonetheless remains surrendered.

Such a framing helps provide a clear picture of the ongoing dependency of Pacific states on former colonial powers and the concomitant appeal to creative cultural autonomy as a source of agency and resistance. It is not simply that the elites of Pacific countries manipulate culture to preserve the status quo, but more critically that the retreat to an autonomous, sovereign space of culture is essential for sustaining these same class relations. What is required, then, is neither for the Pacific to claim a place at the core of global

28 Greg Fry and Sandra Tarte, The New Pacific Diplomacy (Canberra: ANU Press, 2015); see also, Tess Newton Cain and Wesley Morgan, 'Strengthening Australia's Relationship with Countries in the Pacific Islands,' Policy Brief, Griffith University, n.d.

29 Giri, 'Parasitic Anti-Colonialism.' 
capitalism, nor some cultural autonomy from it. Rather, what is required is attention to the identification of new 'cultures', or new political forms and subjectivities forged in the course of struggle. As Malama Meleisea, considering ideology in Pacific studies, including his own experiences in turning to neo-Marxism, concludes:

It is time for us to get past pre-formulated solutions and a mentality that would blame everything on to imperialism and the colonial inheritance. It is so much easier to blame the world system for all our problems. It is more difficult to look carefully at what we had once and have now. It is more painful to face and carefully compare our very limited choices. It is harder to look critically at the way in which we ourselves have made choices prior to, during, and since the colonial period. It is harder still to ask why we made these choices and ask where we might still have other options. This should be the real focus of Pacific Studies. ${ }^{30}$

The intervention I make in this paper is to argue that Left politics provides an effective frame through which to rethink, and build anew, political forms for autonomy in the Pacific and guide struggles against capitalism in the region.

\section{A secretariat to a Left political movement in the Pacific?}

So how can a Left political movement in the Pacific be supported? How could it begin to organise itself? What form would it take? What strategies would it deploy? A source of inspiration in helping to find answers to these questions is the former, and incredibly successful, NGO, the Pacific Concerns Resource Centre (PCRC), which emerged in support of the NFIP movement in the 1970s and 1980s. During a conversation I had with the Australian journalist Nic Maclellan, one of the earliest members of PCRC,

30 Malama Meleisea, 'Ideology in Pacific Studies: A Personal View,' in Class and Culture in the South Pacific, 152. 
he described the organisation to me as a 'secretariat to the movement'. It is based on this framing that I propose here the idea of a secretariat to a Left movement in the Pacific as one means though which to build Left political hegemony in the Pacific region.

There are, of course, key differences between the time when the PCRC was established and now. One thing that aided the success of the PCRC was the prior existence of the NFIP movement and the endorsement of PCRC at the Nuclear Free Pacific Conference in Hawai' $i$ in $1980 .{ }^{31}$ Today, in the absence of any sort of anti-capitalist movement in the Pacific, a Left secretariat would effectively need to precede any movement. Second, the enemies of the NFIP movement were clear: those states undertaking nuclear weapons testing in the Pacific, and those continuing to colonise Pacific Island nations. Overthrowing capitalism in the Pacific today is a more challenging task given the all-pervasive nature of its global reach and the absence of clear enemies (noting, however, that overt US and French colonialism remains in some parts of the Pacific). The task of building a new Left in the Pacific may be best supported by bringing the histories and struggles for Pacific autonomy together with Left political ideals, theories, and critiques of power and ideology.

Below, I outline what some possible objectives and core functions of a Left secretariat in the Pacific could be. These proposals are not blue-prints for the future, but rather provisional ideas aimed at stimulating discussion around the creation of a Left secretariat for the Pacific and the kind of form it might take. A Left secretariat could help develop and support a pan-Pacific movement capable of acting within, against, and beyond capitalism. It could seek to support and grow knowledge and action by Left movements, communities, students, and political parties across the Pacific Islands region at the grassroots, national, and sub-regional level. Possible objectives for a Left secretariat in the Pacific could include:

31 Vijay Naidu, 'The Fiji Anti-Nuclear Movement: Problems and Prospects,' paper presented at the United Nations University Conference: 'Peace and Security in Oceania,' Auckland, 3-6 April 1986. 
- Supporting and generating literacy in Left thought and action that incorporates and builds upon the history of Indigenous and class struggles in the Pacific and that enables Pacific peoples to act within, against, and beyond capitalism.

- Supporting and resourcing Left political action within, against, and beyond capitalism and its violent and destructive impacts on the wellbeing of our islands, ocean, and people.

- Building and supporting Left political solidarity across the Pacific Islands region, with the aim of building a radical Left hegemony in the Pacific.

- Developing and supporting Left modes of social production and reproduction towards a pan-Pacific economy.

In pursuit of these objectives, I propose three interrelated core functions of the secretariat: a think tank, education and solidarity building, and resourcing. ${ }^{32}$

\section{Think Tank}

One of the primary tasks of a Left secretariat in the Pacific would be the development of an alternative counter-hegemonic narrative through constructing and propagating a 'Left-literacy' in the region. The rise of the Right in recent years is not simply due to their ability to win (and even manipulate) elections, but to their ability to provide a meaningful ideological narrative to explain the discontent and hardship experienced by the working class and unemployed all over the world. In contrast, the leftliberal narrative of human rights and multiculturalism has failed to provide a meaningful 'cognitive map' for people to navigate their way through hardship and poverty. Such ideological warfare has been waged by rightwing media and think tanks around the world. A key challenge for the Left in this ideological struggle is competing with the vast amount of funding

32 The International Center for Nonviolent Conflict provides a useful model for thinking through how these possibilities might look in practice: https://www. nonviolent-conflict.org/about/our-work/ 
and resources provided to right-wing think tanks and organisations. ${ }^{33}$ Nonetheless, there are several left-leaning think tanks and organisations in Australia (the Australia Institute) and Aotearoa New Zealand (Economic and Social Research Aotearoa), as well as in other parts of the world (for example, Tri-Continental) that this function of the secretariat could be modelled on-adapted, of course, to the specific historical, sociological, and cultural dimensions of the Pacific Islands region.

\section{Education and Solidarity Building}

Building on the evidence and research developed through the think-tank function, a second function of a Left secretariat for the Pacific could be to create spaces for learning, knowledge and experience sharing, and building solidarity between actors across the Pacific. While it is necessary to avoid fetishising technology as holding all the answers, it is nonetheless an important consideration in the Pacific context, where people and islands are separated by vast distances, and opportunities for coming together in person face numerous challenges. There are expanding opportunities for utilising different online platforms for connecting and networking Left politicians, activists, and researchers across the Pacific region. Indeed, the pandemic has resulted in greater use and acceptance of online platforms. There are many examples of online left-wing media, events, and organising emerging today around the world from which to take inspiration from, including YouTube-based television shows by DiEM25 and Jacobin, as well as podcasts, webinars, and conferences such as those recently produced by The World Transformed and Progressive International.

\section{Resourcing}

A third task of the secretariat could be to enable actors within the movement to learn about, to write on, and to take action within, against, and beyond capitalism in the Pacific. This resource support could take on

33 Sue Bradford, A Major Left-Wing Think Tank in Aotearoa: An Impossible Dream or Call to Action? (PhD diss., Auckland University of Technology, 2014). 
a number of different forms, including finance, education, books, training, and professional support (access to lawyers, for example). Providing 'fellowships' to enable activists to undertake research, seek advice, and strategise to further their movement may be another option.

However, beyond these typical forms of resourcing, there are opportunities to explore the creation of alternative economies in the region that can further support the actions and building of the movement. For example, current research and experiments in crypto-economics are examining how it can contribute to developing new social and economic structures, including how to sustain the enthusiasm of a protest movement after everyone has gone home. A concrete example of how this might work comes from the education sector. The Global Centre for Advanced Studies (GCAS) is a self-sustaining educational and research institution based on a collaborative knowledge ecosystem. ${ }^{34}$ Students can earn GCASY (the cryptocurrency of GCAS) by editing, reading, presenting, and sharing, and can subsequently pay for further tuition with the tokens. Further, graduates from degree programs are invited to become co-owners in the institution. Such a model could serve the proposed Left secretariat and help overcome some of the funding challenges typically faced by Left organisations, while also fostering a networked co-ownership of the secretariat itself. 'Members' of the secretariat could receive tokens for engaging in a range of agreed behaviours, including protest actions, producing or circulating Left literature, participating in campaigns or workshops, and so on. These tokens could then be transferred to access support from the secretariat in the ways outlined in the section on education and solidarity building.

\section{Conclusion}

Having been involved in some initial discussions on the proposal above, it seems that while there is much enthusiasm for the idea, there nonetheless remain significant challenges for such a proposal to become a reality. While 
technology can help overcome challenges of distance and funding, the relevance of Left theory and politics to the region has been questioned, even the use of the term 'Left' itself. Further, amongst those who see value in Left politics, there is a general agreement that some 'translation' work should be undertaken (that is, translating and adapting Left theory and ideals to the Pacific context), yet disagreement remains over exactly how this could be done.

These questions notwithstanding, if the region is to effectively deal with its persistent vulnerabilities and dependencies and secure a viable and resilient future, I believe that not only is a Left political movement in the Pacific possible, it is absolutely necessary. A Left secretariat can provide a vehicle for rethinking political autonomy in the Pacific by bringing together Left theory and practice with the history of Indigenous and class struggles. There is much work to be done. 